\section{The effect of habituation and conditioning trials on hippocampal $\mathrm{EEG}^{1}$}

FREDERICK J. BREMNER, Trinity University, San Antonio, Tex. 78212

Comparison of hippocampal EEG during habituation of a neutral stimulus (CS), habituation of a reinforcing stimulus (US), and classical conditioning showed significantly different spectra for these three treatments. It was also demonstrated that spectra of hippocampal EEG data sampled randomly were different from those sampled immediately following either the CS or US.

In a previous publication (Bremner, 1968), it was reported that hippocampal theta rhythm was present during both conditioning and habituation trials, but that there was a statistically significant difference between the dominant frequency of these two conditions. The present study attempts to extend these findings by comparing intertrial interval samples with samples taken just after the CS or just after the US.

It is reasonable to assume, if theta rhythm is a correlate of attention in rats in the fashion maintained by Bremner (1964, 1968), that the presentation of even a neutral stimulus might show an increase in theta rhythm when compared to a sample taken between stimulus presentations.

Moreover, if the conditioning really had some effect on the hippocampal EEG, one might expect that after 100 or so conditioning trials, samples taken after the CS would be similar to samples following randomly presented US trials. Finally, since it has been previously reported (Ford, Bremner, \& Richie, 1969), that differences in hours of food deprivation yield differences in hippocampal EEG patterns during habituation trials, Ss in the present report were tested under different levels of food deprivation during conditioning as well as habituation sessions.

\section{SUBJECTS}

Six male Holtzman rats were used. All Ss were implanted with four stainless steel electrodes: one in each hippocampus ( $3 \mathrm{~mm}$ posterior, $3 \mathrm{~mm}$ lateral, and $3 \mathrm{~mm}$ below the skull) and one in each of the MFB ( $1.2 \mathrm{~mm}$ anterior, $2.1 \mathrm{~mm}$ lateral, and $9 \mathrm{~mm}$ below the skull). Bregma was used as the null point. The head position used was as described by Krieg (1946).

\section{APPARATUS}

The apparatus employed was identical to that reported by Bremner (1968) except that an IBM $360-44$ computer was substituted for the IBM 1800 computer. Details of the apparatus are also given in Bremner \& Ford (1968), Ford, Bremner, \& Richie (1969), and Eddy (1969). In short, the system consisted of an oscillograph, an analog tape deck, and a digital computer with an $\mathrm{A}$ to $\mathrm{D}$ converter attached. All stimulus presentations were controlled by a programmer built from DEC logic modules. PROCEDURE

The experimental design was to test six Ss at three levels of food deprivation (ad lib $\mathrm{N}=2,3 \mathrm{~h} \mathrm{~N}=2$, and $22.5 \mathrm{~h} \mathrm{~N}=2$ ) during three "within" treatments: CS habituation, US habituation, and classical conditioning.

The attempted habituation of the neutral stimulus, later to be used as the CS, used in this report (CS trials) was considerably simpler than that originally reported by Bremner (1968). All of the Ss reported here received long habituation sessions $(6 \mathrm{~h})$ prior to experiencing the other two treatments. For additional information on the noneffect of length of habituation sessions, see Bremner \& Ford (1968). The physical CS, however, was the same as that previously reported, that is, the offset of a $25-W$ incandescent light for a 5 -sec period, during which the ambient light level was $3 \mathrm{~dB}$ below normal. During the CS habituation sessions, the stimulus change occurred every $3 \mathrm{sec}$. The attempted habituation of the reinforcing stimulus (US trials) was conducted by delivering electrical stimulation to the MFB via one of the electrodes implanted in that structure. The US trials were also conducted in a fashion similar to that previously reported (Bremner, 1968; Bremner \& Eddy, 1969). The intensity of the US, presented in four 500-msec pulses with $500 \mathrm{msec}$ between pulses, was unique for each $S$ and was recorded on a microammeter. Values of 50-200 microamps were set by observing the Ss and adjusting the US until $S$ gave an overt UR (head tic). The frequency of the ESB was $700 \mathrm{~Hz}$.

The classical conditioning trials were conducted by pairing the previously described $\mathrm{CS}$ and US in a esintiguous manner. All Ss experienced 500 conditioning trials with an irregular intertrial (ITI). The average ITI was $45 \mathrm{sec}$

Following the completion of the above treatments, the Ss were tested in a Skinner box to see if electrode placement and stimulation parameters were reinforcing. The Ss were then sacrificed and the brains examined in order to verify electrode placement histologically.

The procedure for treating the results was first to pick EEG samples of $1.5 \mathrm{sec}$ duration for each animal from each treatment. These $1.5 \mathrm{sec}$ epochs were then spectrally analyzed in terms of the percentage power lying at each frequency from $0-60 \mathrm{~Hz}$. These spectra were pooled in appropriate categories as follows: CS trials pre- and poststimulus, US trials preand poststimulus, and conditioning trials pre- and poststimulus. These categories were then tested for differences by an analysis of variance, as was the possible hours of food deprivation effect. A more detailed account of sampling procedures is given in Bremner \& Eddy (1969). The acceptability of using an analysis of variance with this type of data is provided by Benignus, Bunce, \& Bremner (1969). Nevertheless, it is important to mention the temporal relationship of samples to the stimuli during each treatment. For example, during the CS trials a sample was taken immediately after the onset of the CS (stimulus-bound sample), while the ITI sample was taken just prior to the onset of the CS. On the other hand, during the US trials, the stimulus-bound samples were taken just after the offset of the brain stimulation, while the ITI samples were taken exactly where the CS would occur during the subsequent conditioning trials. Finally, the stimulus bound samples during the conditioning trials were taken just after the onset of the CS and the ITI samples were taken just prior to the occurrence of the CS. That is, they were sampled exactly as were the CS habituation trials.

\section{RESULTS}

The significant effects of the variables used in this report on 20 randomly picked spectrograms of hippocampal EEG representing each sampling category were: treatments, frequencies, and treatments by

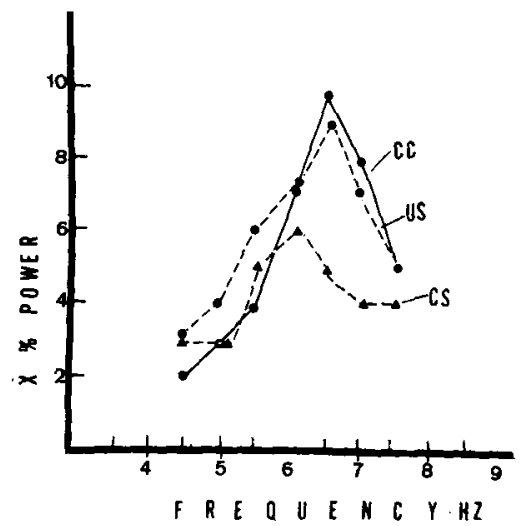

Fig. I. Plot of the frequency distributions of hippocampal EEG for the three treatments employed. 
Fig. 2. Theoretical curves representing the predicted shape of spectrograms of hippocampal EEG resulting from manipulation of different classes of attention variables.

frequencies. The significant treatment effect $(F=9.7, p<.05,2 / 6 \mathrm{df})$ indicates that the hippocampal EEG differs depending on whether the $S$ is being habituated or conditioned. An orthogonal comparison was made of this effect to determine where treatments differed from each other. The results of this test indicated that the conditioning trials and the US trials differed from the CS trials $(F=14.26, p<.01,1 / 6 \mathrm{df})$ more than they differed from each other $(F=4.38$, $\mathrm{p}<.10,1 / 6 \mathrm{df}$ ).

The significant frequency effect ( $F=6.25, \quad p<.005,6 / 18 \mathrm{df})$ simply indicated that there is not equal power at all frequencies (Bremner, 1968). On the other hand, the significant Treatment by Frequency interaction $(F=2.23, p<.05$, $12 / 36 \mathrm{df}$ ) indicates that the frequency distribution of samples of the three treatments is different. Figure 1 is a plot of this effect.

Some of the other variables in this study which had been found significant in previously published studies were not significantly different from chance (particularly hours of food deprivation and sampling period). Therefore, a careful inspection of the group means and individual $S$ scores was made. It was apparent that the sampling-period variable was being biased by one $S$ that showed the effect but opposite to that of the other five Ss. It was decided to test by analysis of variance to see if the sampling periods were significantly different for those Ss showing a sampling-period effect in the same direction. However, the elimination of Ss 003 left one deprivation group with only one $\mathrm{S}$. This problem was solved by pooling the remaining $3-\mathrm{h}$ deprivation Ss with the ad lib $\mathrm{Ss}$, thus collapsing from three levels of deprivation to two. The author considered this legitimate since it has never been demonstrated that there is any significant difference in the EEGs of ad lib Ss and Ss 3-h food-deprived (Ford, Bremner, \& Richie, 1969; Ford, Morris, \& Bremner, 1968; and the present study). All of the variables found significant in the first analysis were also significant in the second analysis, and, in addition, the sampling period variable was also significant $(F=10.77, p<.05,1 / 3 \mathrm{df})$. This indicated that for five of the six Ss tested, there was a difference between the percentage power in the theta range for the stimulus-bound samples and the ITI samples. Nevertheless, the hours of food deprivation effect was not demonstrated.

\section{THEORETICAL THETA CURVES}

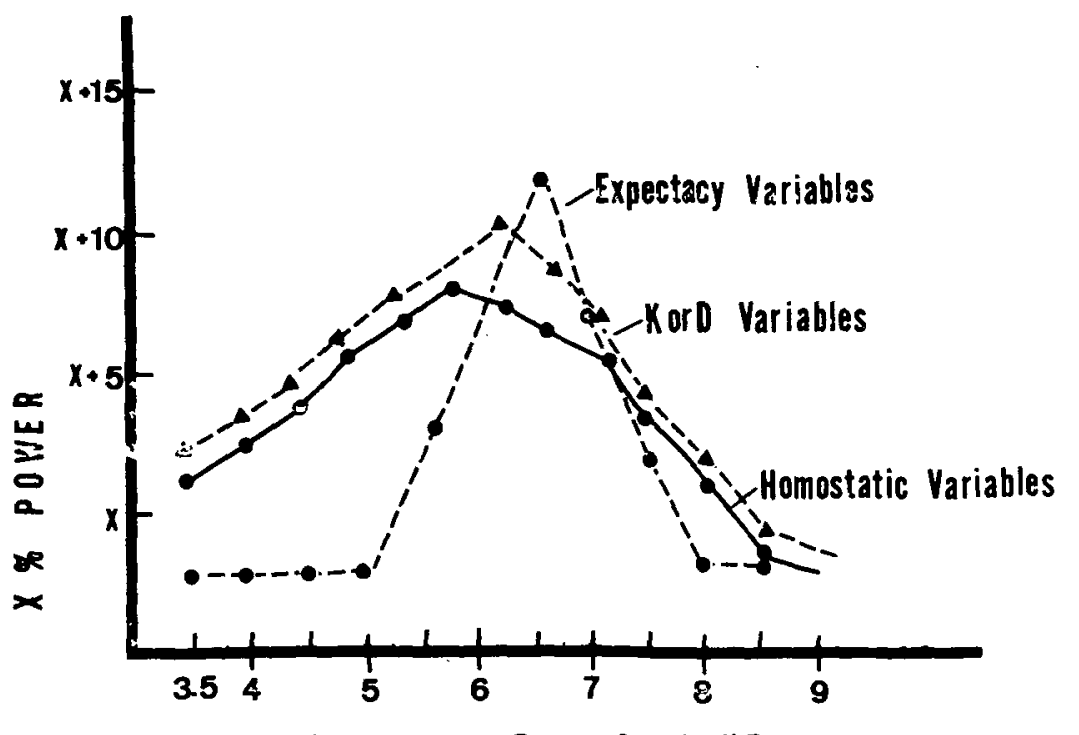

F RE O UEN C Y $-H Z$

\section{DISCUSSION}

The results presented are consonant with those originally presented by Bremner (1968), showing a significant difference between CS trials and classical conditioning trials with regard to hippocampal EEG. In addition, the contention stated in the introduction, that there should be a difference between samples taken just after a stimulus change and those taken irregularly, was supported by the significant sampling period variable. The second contention, that after a series of conditioning trials hippocampal EEG samples would be similar to EEG samples taken immediately after the US, was supported by the significant treatments variable and the result of the orthogonal comparison. Finally, the results also support Bremner \& Eddy (1969), who reported that there was a significant difference between CS trials and ESB trials.

After the publication of an earlier report (Bremner, 1968), a series of descriptive, idealized curves were generated to show the effect of various treatments on hippocampcal theta rhythm. These curves were formally presented at the First Winter Conference on Brain Research (1968). An explanation of the rationale underlying these curves was reported by Ford, Bremner, \& Richie (1969). A reproduction of the curves is given in Fig. 2. Comparison of Figs. 1 and 2 shows that the data approximate the idealized curves. This approximation is even closer for the expectancy (conditioning) curve if the effect of the US on the conditioning data is removed by subtracting the difference between the US and conditioning curves from the conditioning curve. It is possible that the presence of the US has overly influenced the conditioning data by sensitization. If one assumes that this sensitization effect is additive, the above procedure will unbias the data yielding a curve closer to the idealized curve in Fig. 2. The author offers the above only as a working hypothesis since it is difficult enough to demonstrate the effect of even a single variable on EEG data without attempting interactions of two variables. This predicament is nicely demonstrated by the present report, where an hour of deprivation effect was not demonstrated, whereas in a previous study (Ford, Bremner, \& Richie, 1969), in which deprivation was a "within" variable during habituation sessions, its effect on EEG data was significant.

\section{REFERENCES}

BENIGNUS, V. A., BUNCE IJI, H., BREMNER, F. J., BARRATT, E. S., \& FRAZIER, T. W. Significance test for characteristics among multiple spectrum estimates. IEEE Biomedical Engineering Journal, in press.

BREMNER, F. J. Hippocampal activity during avoidance behavior in the rat. Journal of Comparative \& Physiological Psychology, $1964,58,16.22$.

BREMNER, F. J. Hippocampal electrical activity during classical conditioning. Journal of Comparative \& Physiological Psychology, 1968, 66, 35-39.

BREMNER, F. J., \& FORD, J. G. Habituation of neuro-electric responses negative results. Neuropsychologia, 1968, 6, 65-72.

BREMNER, F. J., \& EDDY, D. R. The effect of ESB on hippocampal EEG. Neuropsychologia, 1969 , in press.

EDDY, D. R. The functional relationship between limbic structures: A confirmation and extension. Master's thesis, Trinity University, 1969.

FORD, J. G., MORRIS, M. D., \& BREMNER, F. 
J. The effect of drive on attention. Psychonomic Science, 1968, 11, 156.

FORD, J. G., BREMNER, F. J., \& RICHIE, W. $R$. The effect of hours of food deprivation on hippocampal theta thythm. Neuropsychologia 1969 , in press.

KRIEG, W. J. S. Accurate placement of minutc lesions in brain of albino rat. Quarterly Bulletin, Northwestern University Medical School, 1946, 20, 199-201. NOTE

1. This investigation was supported in part by United States Public Health Service Research Grant NIMH 11618 and 1 Ro3 MH 16824.

\section{Alternation of stimulus and response in three species}

ALAN NEIBERG, JEAN DALE, and DARLENE GRAINGER, University of Michigan at Flint, Flint, Michigan 48503

Adult fish, rats, and college-student $S$ s were given two exposures to a T-maze, followed in $I h$ by two more exposures. One arm of the maze was lighted for the first three exposures with the opposite arm lighted on the last exposure, making possible free-choice alternation followed by forced-choice alternation (i.e., on the last exposure, $S$ was forced to alternate stimuli or responses, but he could not alternate both). Significant free-choice alternation was found only in the case of the rat. Significant forced-choice behavior that produced response variation was found only with those rat $S$ s having alternated in the free-choice situation. An inversion of this latter finding was observed with the fish in that significant forced-choice behavior that produced variation in the stimulus component was found with those fish that had not previously alternated. These findings are discussed in light of current theories of alternation.

Because of its importance for theories of perception and learning, spontaneous alternation (i.e., the tendency for animals to alternate selections in a $\mathrm{T}$-maze) has received considerable attention (e.g., Dember \& Fowler, 1958; Schultz, 1964). Recent failures to find alternation in some species, e.g., the rhesus monkey (Hosoda, 1963), the turtle (Spiegel \& Ellis, 1965), and the chick (Hayes \& Warren, 1963), have raised some questions concerning the phylogenetic generality of the phenomenon. In these studies, however, no distinction was made between two forms of alternation: (1) the tendency to alternate responses in a T-maze and (2) the tendency to alternate sources of stimulation (Fowler, 1965, pp. 32-33). In order for $S$ to be judged as having alternated in the above-cited studies, and in many similar studies where the conventional measurement procedure is used, he would have had to perform in such a manner that he both exposed himself to new stimuli and made a different response.

Although there have been no phylogenetic comparisons of response-alternation tendencies with the tendency to seek stimulus change, Glanzer (1953) has shown that these can be separated experimentally. One way to accomplish this is with a forced-choice procedure. Here, $S$ selects one side of a $T$-rnaze on a first trial and, in the intertrial interval, the cue stimuli are moved to the previously nonselected side. On the next exposure to the maze, $S$ is forced to alternate either (1) by repeating the previous response, thereby exposing himself to the previously nonselected stimuli (stimulus alternation), or (2) by repeating his exposure to the previously selected stimuli, thereby varying his response (response alternation). If, in fact, a species does not show spontaneous alternation, then samples drawn at random from that species should show the same tendency to alternate responses as to seek stimulus change (i.e., significant differences will be absent on the second exposure). In the present study, we used this approach to compare the tendency to seek stimulus change or to vary responses as a function of previous alternation performance among three species of adult Ss.

\section{SUBJECTS}

The Ss were 44 hooded rats, 29 fish [species Trichogaster trichopterus sumatranus (Blue Gourami)], and 26 college students recruited from psychology courses. All Ss were adults.

\section{APPARATUS}

Three T-maze arrangements were created, one for each species tested. The $\mathrm{T}$-maze for the fish Ss was built in an aquarium. It had a $3 \frac{1 / 2}{2} \times 3^{1 / 2}$ in. Plexiglas stem and $5 \times 2 \frac{1}{2}$ in. Plexiglas arms, measured from the choice point. The maze for the rat Ss had a $21 \times 6$ in. wooden stem and $18 \times 6$ in. wooden arms. The maze for the human Ss was created by using a wing of the University that houses the psychology laboratories. The laboratories are arranged in two banks of $4 \times 21 \mathrm{ft}$ each. The corridors leading to the laboratory rooms served as the arms of the maze and were joined by a $5 \mathrm{ft} 2 \mathrm{in}$. $x 9 \mathrm{ft}$ connecting corridor. The entrance to the laboratory wing served as the maze stem. All of the mazes had a dark stem, one dark arm, and one arm that was illuminated by an overhead light source.

\section{PROCEDURE}

The Ss were given a series of four exposures to the maze. Illumination was confined to one side for the first three exposures and was transferred to the other side for the fourth exposure. The side selected for initial illumination was counterbalanced across Ss within species. An interval of $1 \mathrm{~h}$ was imposed between the second and third exposure, but the second and fourth exposures were made with no lag other than that required to remove $S$ from the maze arm and return him to the starting place in the stem.

\section{RESULTS}

On the second exposure to the maze, the first alternation opportunity, significant amounts of alternation (conventionally defined as making a different selection than on the first exposure) were found only with rat Ss, according to the results of a binomial test applied to the side-selected data $(p<.05)$. While $80 \%$ of the rats selected a different arm on this exposure than they had on the first, only $40 \%$ of the fish showed this pattern, and $60 \%$ of the human Ss made a different selection. This rate of alternation in the rat is comparable with that reported by Dember \& Fowler (1958) and is consistent with that found in other observations made in our laboratory and elsewhere (Klein \& Brown, 1969). The first alternation data for the human $S s$ is about at the same level as we have observed in this situation in previous studies. Although others have reported higher alternation rates with human Ss (e.g., Ellis \& Arnoult, 1965; Schultz, 1964), most studies have used younger Ss, and almost all have used finger-maze performance rather than locomotor tasks, and these differences may account for the different rates of alternation. It is difficult to evaluate our fish data in terms of first alternation performance, since adequate literature does not exist.

On the fourth exposure to the maze, alternation of either stimulus or response was forced upon $S$, since he could not repeat the immediately preceding response without confronting new stimuli, and nor could he encounter the same stimuli without varying the response that had immediately preceded. Significant differences in alternation locus (i.e., varying stimuli or response) were not found for any of the three groups. However, closer examination of the 